\title{
Constelações pós-utópicas: sobre a poesia de Haroldo de Campos
}

\author{
Diana Junkes Bueno Martha ${ }^{1}$
}

\section{Algumas balizas}

Este artigo orienta-se por uma leitura da obra haroldiana concernente ao modo pelo qual a tensão utópica configura-se em poemas e transcriações produzidos pelo poeta, tomados também em relação aos estudos críticos que ele desenvolveu. ${ }^{2}$ Assume-se aqui que a utopia, na obra haroldiana, apresenta duas vertentes que coexistem dialeticamente: a de vanguarda, fundamentalmente ligada ao concretismo, que arrefece, mas jamais desaparece; e outra, que se pode denominar de utopia fáustica, mais especificamente vinculada à leitura da tradição, verificada em sua obra e na de Augusto de Campos, bem como nas obras de vários outros poetas, e que estaria relacionada ao que Haroldo de Campos chamou de pós-utopia.

Nesse espectro, e dada a vinculação de Haroldo de Campos à poesia concreta, sua produção recente tem sido lida como se uma passagem da utopia à pós-utopia desse sustentação a seus projetos mais recentes, sobretudo aqueles dos anos 1990 até a publicação de $A$ máquina do mundo repensada em 2000. Entretanto, mais que pensar na substituição da utopia pela pós-utopia, sugerida pelo arrefecimento da primeira e pelo suposto desaparecimento da esperança como princípio norteador dos projetos poéticos - como fazem alguns críticos (Simon e Dantas, 1985; Franchetti, 2000; Pécora, 2005; Siscar, 2014; 2016) -, vale a pena considerar a possibilidade de que utopia e pós-utopia caminham juntas e em tensão na obra de Haroldo de Campos. Sob essa perspectiva, não haveria um segmento de uma para outra, como se fossem fases da obra, mas uma

\footnotetext{
${ }^{1}$ Doutora em estudos literários e professora da Universidade Federal de São Carlos (UFSCar), São Carlos, SP, Brasil. E-mail: dijunkes@gmail.com

${ }^{2}$ Parte importante das reflexões aqui apresentadas vem sendo desenvolvida sob os auspícios da interlocução generosa, instigante e precisa estabelecida com o prof. Keneth David Jackson, da Universidade de Yale, a quem sou imensamente grata. Essa interlocução teve início em 2012, durante período em que fui Visiting Fellow, em Yale, com Bolsa de Pesquisa no Exterior/Fapesp. Agradeço, ainda, ao Centro de Referências Haroldo de Campos - Casa das Rosas Espaço de Poesia e Literatura/Poiésis, pela bolsa pesquisador recebida em 2015, que viabilizou um avanço significativo na compreensão da pós-utopia haroldiana, favorecido pela pesquisa no acervo do poeta.
} 
dialética na qual, a partir de certo momento, a partir dos anos de 1970, uma integra a outra. Da perspectiva deste artigo, a relação entre ambas é bem mais complexa do que se pode julgar, se não houver, do ponto de vista da crítica, a preocupação em situar as produções dos últimos anos em perspectiva histórica na obra do próprio poeta, o que evitaria, por exemplo, tomar a preocupação com a leitura da tradição ou mesmo com a forma fixa como algo do Haroldo envelhecido. Ou seja, se a leitura da tradição sempre esteve presente para o concretismo, a importância que assume a partir do momento em que o poeta enuncia a pós-utopia concerne a um aprofundamento, especialmente viabilizado pela tradução, e não apenas a uma mudança de paradigma poético, que abandonaria a invenção em prol de uma leitura do passado.

Cabe ao estudioso observar a obra haroldiana tanto em sua vertente poética como em relação à crítica e à tradução a partir de uma dimensão mais ampla e menos circunscrita a particularizações e, muitas vezes, ao dizer do próprio poeta, embora não se possa deixar de considerar sua postura diante da vanguarda e da pós-utopia como orientadores de leitura. Como afirma Costa Lima (2005), transformar em dogma as ideias de um inventor, como é Haroldo, seria minimizar o alcance de seu pensamento crítico. Aceitar as instâncias de sua atuação como fonte de reflexão acerca de suas contribuições e, ao mesmo tempo, questioná-las, sem sacralizá-lo ou dessacralizá-lo, e/ou sem minimizar sua importância no cenário da poesia brasileira da segunda metade do século XX, é um meio de fazer prosseguir as pesquisas sobre sua obra em dimensão crítica e produtiva, em especial na relação com a história e por meio dos diálogos estabelecidos fora do país com escritores, filósofos e pensadores de várias áreas do conhecimento. ${ }^{3}$ Neste artigo, por força das considerações acerca do pensamento haroldiano, sua voz será convocada mais de uma vez, porém, é importante sublinhar que essa convocação leva em conta as nuances desse mesmo pensamento ao longo do tempo. O que o poeta afirma no texto sobre a pós-utopia (Campos, 1997) não é suficiente para avaliar a construção desse conceito em sua obra. Além disso, a crítica da obra do poeta ainda mobiliza pouco alguns textos publicados sobre ele no exterior, como os de David Jackson, Charles

\footnotetext{
${ }^{3}$ A revista Cisma, da Universidade de São Paulo, publicou um número especial (2015, ano IV) com testemunhos sobre Haroldo de Campos de Octavio Paz, Jacques Derrida, Cabrera Infante, João Cabral de Melo Neto. Alguns muito breves, outros de fôlego maior, como é o caso de Derrida. O pequeno volume da revista atesta a necessidade da consideração desses diálogos de modo mais efetivo.
} 
Perrone e Marjorie Perloff, para citar alguns, que serão mencionados neste artigo. Em consequência dessa leitura mais circunscrita à crítica nacional, também não se atenta para as passagens do poeta por universidades americanas e europeias, o que restringe as leituras de seus textos, em especial, aqueles inseridos no âmbito da pós-utopia.

\section{Invenção, tradição e tensão da "utopia pós-utópica"}

A invenção, para a poesia concreta, não se separa da revisão do passado, crítica, sistemática, desconstrutora, ruptora, ou seja, a invenção das formas é dependente de uma reinvenção do cânone. Não se trata de negá-lo, como teriam feito as primeiras vanguardas, mas de tirar proveito de parte desse cânone que merece vigorar para as gerações futuras, nos termos do make it new poundiano (Pound, 1970). ${ }^{4}$ Desse modo, o movimento da poesia concreta poderia ser avaliado, em sua inquestionável força de vanguarda, sob outros prismas. O concretismo, ao romper com as formas do presente, em um momento histórico propício a seu surgimento - o Brasil da Era JK (Campos, 1992a; Aguilar, 2005) -, rompe também com o estado de coisas estabelecido, mas não a ponto de congelar uma história literária negada porque carente de sentido, como talvez tenham feito algumas vanguardas, mas de retirar dela o que contribui para a ação presente. Essa diferença é crucial para entender a singularidade das ações e a renovação propostas pelo Grupo Noigandres. A religião do concretismo, se houve, não foi a futurologia pura e simplesmente, mas a de seu tempo.

Para os poetas concretos, o significado de "ser absolutamente novo" dizia respeito não apenas à radicalidade da experiência - coletiva e programática, no âmbito do concretismo -, mas ao mesmo tempo, a um discurso que não deixa de rever o próprio discurso das vanguardas. Em gesto de leitura crítica que caracterizou a poesia concreta, liga-se ao passado de modo íntimo e inventivo, para ampliar o repertório, como afirma o poeta em 1968:

\footnotetext{
${ }^{4}$ Para perspectivas sobre as formas de atuação das vanguardas, consulte-se, entre outros, Teles (2012), Poggioli (2011), Bürger (2008) e Schwartz (2008). Sobre o concretismo em particular, dentre os inúmeros trabalhos existentes, pode-se consultar Franchetti (2012) e Aguilar (2005).

${ }^{5}$ Texto publicado originalmente em 14 de setembro de 1968 no Suplemento Literário d'O Estado de S. Paulo. Citado neste artigo conforme reproduzido em A arte no horizonte do provável (Campos, 1977a).
} 
Ampliação do repertório significa também saber recuperar o que há de vivo e ativo no passado, saber discernir no mole abafante de estereótipos que é um acervo artístico visto de um enfoque simplesmente cumulativo [...]. Todo presente de criação propõe uma leitura sincrônica do passado e da cultura. A apreensão do novo representa a continuidade e a extensão da nossa experiência do que já foi feito, e nesse sentido "quanto mais nós compreendemos o passado, melhor nós entendemos o presente". Uma forma do teórico da comunicação Collin Cherry que casa com o lema poundiano: Make it new (Campos, 1977a, p. 154, grifo nosso).

Do ponto de vista do que seja a vanguarda, coloca-se aí uma questão interessante. A leitura da tradição não será melancólica, mas historicamente ativa, situada. Em 1968, apesar de não haver ainda conceituado a pós-utopia, Haroldo já estava em contato intenso com as leituras da obra de Walter Benjamin e atento a um modo de conceber a história a partir de uma revisão do passado, bem como estava em diálogo com Roman Jakobson e a questão da substituição sincrônica dos estilos na história literária. Para Haroldo de Campos, dois são os modos pelos quais a apropriação do cânone é feita: o paideuma, que é um procedimento de seleção e leitura do passado; ${ }^{6}$ e a poética sincrônica, que estabelece uma forma de elaboração da história literária a partir de uma perspectiva não diacrônica de leitura de autores e obras.

O paideuma foi um instrumento da vanguarda concretista, entre outros, que garantiu o projeto amplo de renovação da linguagem em questão, na medida em que, ao resgatar autores do cânone que foram ruptores em relação à época em que produziram, os poetas concretos mobilizaram também suas propostas em seu movimento. Publicado em Noigandres 4, o "Plano-piloto da poesia concreta" estabelece um paideuma: Mallarmé, Joyce, cummings, futurismo, dadaísmo, Oswald de Andrade, Cabral, poesia-ideograma (Pound/Fenollosa). Explica Haroldo de Campos, em texto de 1960,7 "Contexto de uma vanguarda": ${ }^{8}$

\footnotetext{
${ }^{6}$ Segundo Pound (1970, p. 161), paideuma é "a ordenação do conhecimento de modo que o próximo homem (ou geração) possa achar, o mais rapidamente possível, a parte viva dele e gastar um mínimo de tempo com itens obsoletos".

${ }^{7}$ Texto escrito para a introdução a uma antologia do grupo concreto de Fortaleza. Utiliza-se aqui o texto reproduzido em Teoria da poesia concreta (Campos, 2006).

${ }^{8}$ A esse respeito, ver Jackson (2005).
} 
Não há panorama mais fiel do mundo contemporâneo, cujas distâncias diminuíram, cujos problemas se interligam, cujo patrimônio mental é cada vez mais posto em termos universais, como se verifica cotidianamente no campo da ciência. Surgem nele as condições para uma linguagem comum. Por que deveria a arte estar fora desse quadro? Um produto de luxo, a ser cultivado numa estufa artesanal, salvaguardado dos contatos com o mundo exterior como uma flor exótica? Os grandes poetas da língua, na fase áurea do mundo luso, como Sá de Miranda e Camões, não foram porventura homens contemporâneos em seu tempo, vivendo com a informação adequada, importando provençais, italianos e espanhóis e exportando poesia em língua portuguesa criativa e qualitativamente enquadrada no contexto da época? A poesia concreta fala a língua do homem de hoje [...]. Pela primeira vez [...] a poesia brasileira é totalmente contemporânea (Campos, 1960/2006, p. 211, grifo nosso).

Nesse sentido, pelo menos enquanto projeto, não se nota no concretismo o fundamentalismo do futuro, como é comum às vanguardas ao pressuporem que o devir traria soluções para as carências do presente (Moriconi, 1986, p. 75). ${ }^{9}$ Se por um lado a reinvenção crítica de precursores é força motriz da vanguarda concretista, juntamente com a renovação das formas, por outro lado, o paideuma orienta o presente da criação. Observe-se na citação anterior o número de vezes em que a palavra contemporâneo aparece no discurso de Haroldo sobre a poesia concreta; um contemporâneo que foge da "clicherização do procedimento inovador" (Moriconi, 1986, p. 75), pensado em termos críticos e em função do presente, ainda que, sim, como projeto de futuro para a linguagem, as formas, a poesia como "princípio-esperança. ${ }^{10}$

\footnotetext{
${ }^{9} \mathrm{O}$ artigo de Moriconi aqui referenciado é pioneiro sobre a pós-utopia haroldiana.

10 Segundo Bloch (2005), o princípio-esperança funda-se nos sonhos diurnos, aqueles que sonhamos acordados e conscientes e que revelam a busca de um mundo melhor, impulsionando-nos à ação. Amplamente inspirado pela interpretação dos sonhos freudiana, como Benjamin e outros da mesma geração, Bloch propõe, em oposição aos sonhos noturnos, a construção de sonhos diuturnamente. A localização espacial desses sonhos é também para ele fundamental, daí a importância dada à geografia, aos descobrimentos, às utopias de um mundo novo. O princípioesperança emerge, pois, da consciência de que é possível a construção de um mundo melhor. Ver também Carlos Eduardo Jordão Machado (2008).
} 
Caberia perguntar, então, o quanto já havia, no bojo dos preceitos da poesia concreta, uma percepção de que o futuro buscado como o lugar utópico deveria ser pensado de modo crítico. Ainda que muito calcado na utopia e alimentado pela esperança, ampliada, claro, pelo contexto político e social do qual emerge o movimento, é possível afirmar que os concretos jamais se deixaram seduzir pelo idealismo do futuro. Destarte, o princípio-esperança que alimentou essa vanguarda foi também incorporado criticamente e, ainda que ceda espaço ao princípio-realidade, a esperança persistirá na fase pós-utópica, como reproposição de preocupações que já estavam em curso. Por isso, desse ponto de vista, é discutível afirmar, como fazem Iumna Simon e Vinícius Dantas (1985), que o Haroldo pós-utópico é desesperançoso:

Embora nem tão desencantada, a constatação de Haroldo de Campos [no ensaio sobre a pós-utopia] toca em um ponto vital: a ausência, no horizonte da criação poética, de qualquer vestígio de esperança, de projeto ou prática transformadora. [...]. Na nova realidade, o futuro nada mais augura [...]; mas para o antigo concretista a poesia persiste sendo uma experiência digna e válida, uma experiência de "concreção sígnica" que ainda pode desafiar a desesperança e possibilitar a derradeira norma de ação. (Simon e Dantas, 1985, p. 51). ${ }^{11}$

A citação mostra que os autores deixam-se levar por alguns trechos do discurso haroldiano e os argumentos para a desesperança, que atribuem ao poeta, acabam por se fragilizar em sua própria avaliação do ensaio de Haroldo. Quando se lê que, de um lado, o poeta sustenta "a ausência de qualquer vestígio de esperança", mas afirma-se também que a constatação "não é tão desencantada" e que há, para Haroldo, segundo o excerto acima, a possibilidade de a poesia "desafiar a desesperança", deve-se perguntar, afinal, se há mesmo para Haroldo a ausência de qualquer vestígio de

\footnotetext{
${ }^{11}$ A despeito do inegável mérito do trabalho citado e de sua relevância como reflexão sobre o cenário da poesia brasileira no período (anos 1980), é importante pontuar que as referências a Haroldo de Campos são, por vezes, apressadas. Por exemplo, menciona-se que o poeta concreto apenas em 1984 preocupou-se com a pós-utopia (Simon e Dantas, 1985, p. 50). Como se verá neste artigo, Haroldo afirma em entrevista que essa preocupação surge, para ele, em meados dos anos 1970, a partir de Octavio Paz. Além disso, a primeira menção de Haroldo à pós-utopia é de 1979, ano em que a Lei da Anistia estava em curso e cinco anos antes da publicação do ensaio a que se referem Simon e Dantas. Portanto, é no estrangulamento do regime militar e no auge das discussões sobre a Guerra Fria que essa questão passa a preocupar o poeta. Por fim, a reformulação do conceito de história a partir de Walter Benjamin é ainda anterior, de fins dos anos 1960, e irá respaldar, nos anos 1970, a construção do conceito de pós-utopia.
} 
esperança. Parece inegável que embora haja uma mudança de perspectiva e a falência dos ideais utópicos de esquerda - vinculados ao marxismo, responsável pela sensação de desalento -, há a reafirmação da poesia como forma de manutenção de uma utopia outra, aquela que vem após a utopia do futuro ideal, qual seja, a pós-utopia. Por mais que se tente enquadrar o discurso haroldiano nesse ensaio como desesperançoso, é o próprio discurso do ensaio que resiste a esse enquadramento.

No ensaio sobre a pós-utopia, Haroldo de Campos sustenta que: "Sem esse princípio-esperança, não como vaga abstração, mas como expectativa efetivamente alimentada por uma prática prospectiva (os sonhos diurnos), não pode haver vanguarda entendida como movimento [...]. Sem perspectiva utópica, o movimento de vanguarda perde o seu sentido" (Campos, 1997, p. 266-268). Por um lado, sugere que, ao princípio esperança de Bloch, coloca-se, a partir de meados dos anos 1970, o princípio realidade. ${ }^{12}$ Pelo modo como Haroldo apresenta a questão, o leitor pode ser levado a crer que há, de fato, uma passagem de utopia a pós-utopia, no sentido de ruptura. Por outro lado, considerando o que o poeta diz no mesmo texto, em outros momentos, e nos ensaios sobre a comunicação e o contexto de vanguarda, anteriormente citados, caberia questionar em que medida o concretismo como vanguarda já não traria, ao menos para Haroldo de Campos, o germe do princípio-realidade.

Note-se que, propositalmente, o que se está problematizando é o dizer do poeta, na esteira do que propõe Costa Lima, citado no início deste artigo. Desse modo, supor apenas a passagem da utopia para a pós-utopia restringiria o alcance da reflexão de Haroldo nesse ensaio e no conjunto de trabalhos que desenvolve a partir dos anos 1960. O projeto da vanguarda concretista vincula-se grandemente aos sonhos diurnos de Bloch, jamais descolados de seu tempo, sempre contemporâneos e propositivos (Machado, 2008). Para Bloch, entretanto, a mudança futura só vem pela consciência presente, embora esta esteja totalmente voltada para construir o idealismo do futuro:

Bloch busca demonstrar que o espírito utópico, embora pareça estar divorciado da realidade presente, vislumbra que o "aqui e agora" é preocupante; isto é, a utopia deixa margem a uma real crítica do presente [...]. Se a esperança é o princípio pelo qual o homem

\footnotetext{
${ }^{12}$ Aqui Campos se refere ao princípio realidade freudiano, que se opõe ao princípio do prazer e concerne a dar conta das exigências do mundo real, onde há necessidade e escassez (Freud, 2010). Note-se que, assim como em Bloch, Freud é uma referência, dessa vez pela via da realidade e não do sonho.
} 
supera subjetivamente o real, ultrapassando-o no momento que permite a tensão para o futuro, isto não significa afirmá-la como princípio abstrato [...] o futuro deve ser construído objetivamente sobre condições históricas (Vieira, 2000, p. 1).

A leitura do excerto mostra o quanto as proposições da poesia concreta afinam-se com a perspectiva de Bloch. A mudança de perspectiva mais importante entre o concretismo e a pós-utopia reside, portanto, em dois aspectos: i) considerar que o futuro, ainda que construído objetivamente, não é um lugar ideal, e que a construção objetiva deve levar em conta o presente e não o futuro em si, pois este, nessa perspectiva passaria a ser desdobramento do presente; e ii) a partir desse reposicionamento das possibilidades do futuro, a historia se abre, tornando-se plural - em sentido benjaminiano. $O$ que muda, efetivamente, segundo a leitura do ensaio de Haroldo sobre o poema pósutópico, é que se passa a pensar no agora em virtude de um necessário adensamento do tempo presente, que impõe a leitura crítica do passado, no sentido do Jetzeit benjaminiano e das teses "Sobre o conceito de história" (Benjamin, 1986). ${ }^{13}$ Sob essa perspectiva, o futuro importa menos como possibilidade de realização, como importaria para Bloch, na medida em que virá apenas se o agora o tornar viável; em outras palavras, o foco passa a estar no presente, mas não deixa de mirar o futuro - assim como antes o foco estava no futuro e não ignorava o presente. Outra diferença importante é que, se antes o passado era lido como paideuma, na pósutopia é a perspectiva sincrônica que orienta a leitura. Ignorar o peso do futuro nessa opção pós-utópica pode ser precipitado. Quem faz os exercícios de transcriação como Haroldo faz, quem se alimenta do gesto mefistofélico de leitura do cânone e quem fausticamente entrega-se à poesia como faz Haroldo até seus últimos dias nunca deixa de ter um

\footnotetext{
${ }^{13}$ Em sua tese de doutorado, Fabio Weintraub (2013, p. 167-169) traz, a partir de apontamento de aula de Iumna Simon, um interessante questionamento sobre a vinculação da pós-utopia ao Jetzeit de Walter Benjamin. Para a crítica, segundo aponta Weintraub, a agoridade haroldiana é permansiva e recai na homogeneidade e no vazio, não advogando oposição às tradições vencidas, tampouco lidando com a heterogeneidade em termos de hibridização. Essa discussão foge ao escopo do presente artigo, mas é importante ressaltar que, em linhas gerais, discorda-se da posição de Simon, na medida em que do ponto de vista aqui adotado, a agoridade haroldiana guarda muito da centelha de Benjamin, tanto pela seleção do passado, daquilo que deve "relampejar" ao revisar tradições esquecidas ou colocadas à margem do "cânone" estabelecido, quanto porque, por meio da tradução encena sua ação revisora e recusa a preservação do cânone pura e simples, mas, ao misturar Safo e Sá de Miranda, Joyce e Dante, impõe novas formas de reflexão no presente, a partir de escolhas do passado, como propõe Benjamin.
} 
projeto de mudança e, consequentemente, de futuro, mesmo que essa ideia apareça submetida à poética da agoridade em razão da imposição do princípio-realidade. Leyla Perrone-Moisés em Altas literaturas (2003) chama também a atenção para esse fato.

A poesia da agoridade não é antifuturo, mas, como diz Haroldo de Campos, é "crítica do futuro e de seus paraísos sistemáticos" (Campos, 1997, p. 266), que se mostraram, por mais que fossem pensados a partir do presente, irrealizáveis. É nesse sentido que se afasta de Bloch, que pensa a utopia em um momento em que o futuro era marcado pela aura de um devir ideal, ainda que fosse construído objetivamente no presente. A pósutopia corresponde a desauratização do futuro, não à sua negação.

A reivindicação da agoridade, no momento em que Haroldo passa a se preocupar com a pós-utopia, é resultante da observação das crises nacional e mundial. ${ }^{14}$ Trata-se da constatação de que, por mais que o presente projete o futuro, por mais que se transforme para construí-lo do melhor modo, a experiência das sociedades (brasileira, mundial) mostra que as tentativas levaram ao insucesso, e a poesia pós-utópica procurará responder a esse momento propondo outro gesto: o da leitura crítica do passado.

Frize-se, portanto, que em movimento distinto daquele observado nas vanguardas históricas, o concretismo lidou com o passado de modo ativo e

\footnotetext{
${ }^{14}$ Uma das primeiras menções à pós-utopia é feita em 1979, em Deus e o diabo no Fausto de Goethe, mais especificamente no ensaio "Bufoneria transcendental: o riso das esferas": "Estamos em uma época que já há quem chame de 'pós-moderna', mas que inegavelmente poderá ser melhor definida como 'pósutópica"' (Campos, 2005a, p.176). Não se deve esquecer que, em termos de leitura crítica e antropofágica do passado, Haroldo trata, nessa obra, de plagiotropia, conceito sobre o qual não se vai ater aqui. Em 21 de agosto de 1983, Haroldo concede uma entrevista ao editor de Folhetim, Rodrigo Naves, republicada em Metalinguagem e outras metas sob o título de "Minha relação com a tradição é musical" (Campos, 1992b). Nessa entrevista, um ano antes do texto em homenagem a Paz, Haroldo menciona a pós-utopia, a partir de sua leitura de Os filhos do barro, de 1974. Essa discussão é motivada pelo contexto da entrevista. Deve ser destacado que o Movimento Diretas Já, pela abertura democrática no Brasil, foi de março de 1983 a abril de 1984; a Lei da Anistia, por sua vez, é de 1979; e, em 1974, quando Haroldo entra em contato com o texto de Octavio Paz, o "milagre brasileiro" e o crescimento em "marcha forçada" entrevam em declínio, revelando, ainda mais, as atrocidades do regime militar e de sua ideologia nacionaldesenvolvimentista. A preocupação é justamente pensar que o mundo proposto pelo comunismo malogrou e que, por outro lado, nada ficou no lugar dele, a não ser a crise da Guerra Fria. A situação econômica do Brasil, finda a ditadura, era periclitante. A desilusão ou, ainda, a recolocação do princípio esperança tem a ver com a frustração de um projeto segundo o qual o presente seria o meio para construir um futuro melhor. O que se constata, historicamente, é que o presente havia se tornado tão urgente que à esperança impunha-se a realidade, ou seja, o adiamento do futuro como projeto, já que esse gesto acabou por anular o próprio presente do qual era erigido. A título de curiosidade, lembre-se de que é de 1984 o poema Pós-tudo, de Augusto de Campos, que segue o mesmo tom pós-utópico, mas jamais antiutópico.
} 
inventivo, revisitando-o criticamente pela via do paideuma. Desse modo, o que a poética pós-utópica faz é retornar à utopia da vanguarda concretista (sem se opor a ela), buscando, naquele momento, não tanto a renovação das formas - processo já bastante bem-sucedido à altura das proposições de Haroldo sobre a pós-utopia -, mas modos de ler a tradição para além do procedimento fornecido pelo estabelecimento de um paideuma, sendo necessária a incorporação, a esse procedimento, de uma concepção de leitura que desse conta dos desafios impostos pelo momento histórico. Assim, mesmo que o poeta diga no ensaio que não há mais utopias que sustentem fortemente as vanguardas, o que é procedente, como se sabe, há que se pensar que isso não anula o fato de que uma das linhas de força da utopia da poesia concreta migra para a pós-utopia, qual seja, a leitura da tradição, intensificando-se. Portanto, a relação de uma com a outra não é linear, diacrônica, mas sincrônica; melhor ainda, dialética.

É, porém, a entrevista a Rodolfo Mata que ajuda a perceber o senso crítico dessa "utopia-pós-utópica" em Haroldo de Campos, que não nega, em termos artísticos, as conquistas do concretismo, mas que relativiza seu alcance como resposta a um contexto historicamente diverso daquele que $o$ originou. Vale a pena a longa citação:

Houve um momento, então, em que percebi - estávamos nos anos 70 - que mundialmente e no Brasil havia uma crise das certezas ideológicas. Octavio Paz também observaria isso. Paz faria uma crítica ao futuro, afirmando que, em nome exatamente de um futuro idealizado, as necessidades do presente acabaram sendo esquecidas, e, em nome de "paraísos" totalitários, acabaram sendo negadas as tentativas de realização do "aqui e agora". [...] A utopia perde um pouco dessa ideia visionária de ficar projetando para o futuro aquilo que não pode realizar no presente, mas mantém sua dimensão crítica e, através dessa dimensão crítica, pode fazer a recuperação de certas tradições do passado, que não haviam tido condições de prosperar, e oferecer instigações para o presente. E eu não vejo essa operação como um nostálgico e eclético retorno ao passado. [...] Se me perguntassem: "o senhor é de retaguarda ou de vanguarda?", eu responderia: "sou de vanguarda". Mas "vanguarda" não é um termo satisfatório. No meu modo de ver, vanguarda hoje não exprime exatamente a atitude da consciência crítica pós-utópica, pela qual me interesso. Porém, se eu tiver que optar em uma disjunção retaguarda-vanguarda, é evidente que direi sempre que meu trabalho representa uma vanguarda e sustentarei isso. Representa a vanguarda possível em um quadro pós- 
utópico. De modo nenhum é um trabalho que cultiva a nostalgia essa sim de retaguarda -, que se interessa por uma restauração eclética, de tudo permitido, de "vamos voltar ao soneto", nada disso. Essas posições nostálgicas são "acríticas" e não me dizem respeito (Campos,1994, s.p., grifo nosso).

O engajamento aqui é patente: como a arte responde aos desafios do momento histórico? Esse questionamento insta Haroldo de Campos a rever a história da literatura brasileira como uma tentativa de proposição de uma história plural e também de autodefinição bastante análoga à proposta de Paz (1996a). ${ }^{15}$ Vai nessa mesma linha a citação que o poeta faz no ensaio sobre Goethe. Diz Haroldo, a partir de Vittorio Strada: "à utopia da verdade monológica, opõe-se a verdade dialógica da utopia, onde o utópico perde a sua pretensão total e totalitária e se manifesta na sua ambivalência e ambiguidade, tornando-se parte da comunicação intersubjetiva na busca de um mundo diverso e na crítica do mundo atual" (Strada apud Campos, 1979/2005a, p. 177). Nessa mesma perspectiva, argumenta Moriconi (1986) quando diz que a ideia de futuro é totalitária e minimiza as pluralidades. É importante destacar que a pósutopia repropõe a utopia, sem negá-la, resgatando uma poética de liberação da subjetividade e da imaginação por meio da valorização do agora e das histórias plurais (Moriconi, 1986, p. 80). A ideia é bastante devedora das proposições benjaminianas no que concerne a trazer à luz elementos da história que ficaram encobertos, instaurando possiblidades de outro devir que se estabelecerá pela ressignificação do passado (Gagnebin, 2014, p. 206). A visão de história de Walter Benjamin (1986) é aberta e é por isso que o passado pode ser resgatado a partir de novos relatos, de outras perspectivas, por exemplo, pela dos vencidos, instaurando uma nova visão de um passado outrora estanque.

Parece bastante pertinente propor que o importante ensaio " $\mathrm{Da}$ razão antropofágica, diálogo e diferença na cultura brasileira", publicado em 1981, guarda afinidade com a visão da história de Walter Benjamin ao mesmo tempo que passa a estabelecer as

\footnotetext{
${ }^{15}$ O ensaio mencionado foi publicado em 1981 nos seguintes periódicos: Colóquio Letras, n. 62 (Lisboa); Vuelta, n. 68, 1982 (México); Vuelta Sudamericana, n. 4, 1986 (Buenos Aires); Latin American Literary Review, n. 27, 1986 (University of Pittsburgh); Lettre internacionale, n. 20, 1989 (Paris); Lettera Internazionale, n. 20, 1989 (Roma); Lettre intenacional, n. 11, 1990 (Berlim); e Biblioteca Mario de Andrade, v. 44, n. 14, 1983 (Brasil).
} 
proposições acerca da pós-utopia. Ou seja, se de um lado existe a consciência do esgotamento das possibilidades utópicas tal como se apresentavam, de outro, elas sustentam o projeto da constituição de uma "Antologia da literatura brasileira de invenção" (Campos, 1992a) como meio de pensar as poéticas possíveis. A pós-utopia, por isso, não é disfórica; antes, instiga o poeta a escrever um dos mais importantes ensaios sobre nossas literatura e cultura.

Em carta escrita a David Jackson, ${ }^{16}$ seu amigo e companheiro intelectual, em setembro de 1980, o poeta argumenta que havia finalmente chegado a um bom termo no sentido de reunir suas reflexões anteriores para propor bases para uma historiografia da literatura brasileira, sendo esse modo análogo, guardadas as devidas proporções, ao que acontecia em outras culturas latino-americanas. O poeta remetese, nesse caso, ao texto de Paz, "Invenção, desenvolvimento, modernidade" (1996b). ${ }^{17}$ O entusiasmo de Haroldo na referida carta deixa patente o grande passo dado em termos da construção e sistematização de seu pensamento sobre o lugar de nossa literatura e de nossa cultura, a partir do que chama de nacionalismo modal (a ruptura em lugar do traçado linear) em oposição ao nacionalismo ontológico e logocêntrico. Veja-se a carta: ${ }^{18}$

\footnotetext{
${ }^{16}$ Agradeço a David Jackson a generosidade e o compromisso acadêmico com que disponibilizou para a divulgação a carta que lhe enviou Haroldo de Campos. Uma das mais importantes escritas pelo poeta, já que anuncia o fundamental ensaio sobre a razão antropofágica. Também é importante notar que é da experiência fora do Brasil e da possibilidade de interlocução no exterior que o ensaio toma corpo, em especial pelo convívio com David Jackson, à época na Universidade de Austin, e diálogos também com Octavio Paz.

${ }^{17}$ Texto escrito entre 1964 e 1971. Utiliza-se aqui a edição em português, publicada em Signos em rotação (Paz, 1996b).

${ }^{18}$ Albert referido na carta é Albert G. Bork, na época aluno de pós-graduação em literatura brasileira na University of Texas at Austin, quando esteve lá HC pela primeira vez em 1970. Em parceria com David Jackson, traduziram Serafim Ponte Grande (Seraphim Grosse Pointe, Austin, New Latin Quarter Editions, 1979). Haroldo faz ainda referências a Benedito Nunes e sua esposa, Maria Sílvia, e manda lembranças a Bete (Elizabeth Jackson). Assina em nome dele, de D. Carmen Campos e Ivan, seu filho. A afetividade mostra o grau de amizade entre ambos os interlocutores. O texto que seria publicado em revista alemã, acabou por ser veiculado, inicialmente, na Colóquio Letras, de Lisboa, com o subtítulo: "A Europa sob o signo da devoração", o que se afinaria com o título da publicação alemã mencionada na carta. Até a presente data não se localizou no acervo a publicação alemã. Haroldo de Campos refere-se ao período em que esteve em Austin, em 1970. Depois, em 1981, retorna a Austin e ministra disciplina usando o ensaio que menciona na carta. O relato desse segundo período de visita foi feito por Charles Perrone, hoje professor da Universidade da Florida, e pode ser lido na revista Transluminuras, da Casa das Rosas - Espaço Haroldo de Campos de Poesia e Literatura, disponível em: http://www.casadasrosas.org.br/crhc/arquivos/transluminura1.pdf
} 
Heu cono ravid:

Aqui lhe envio o ensaio que gottaria de ter traduzido para

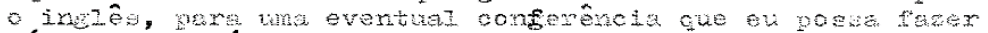

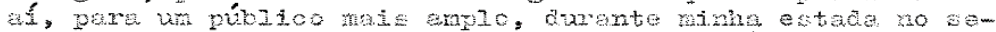

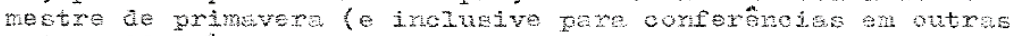
minersids

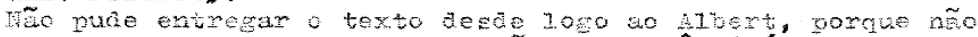

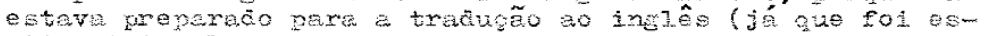

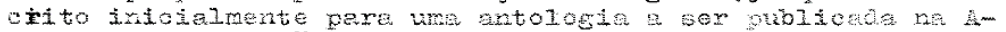

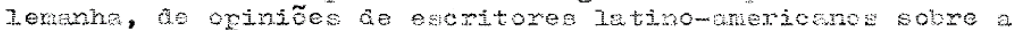
oultura européia).

Qura facilitar o trabalho de trafugão, anexo un elenco de 5

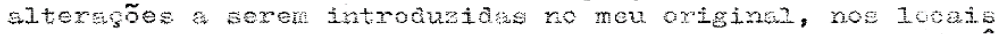

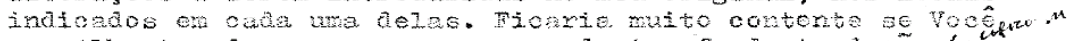

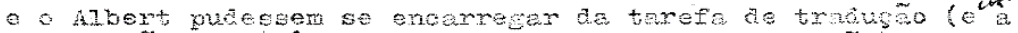

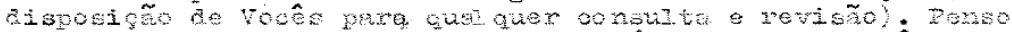
quo, ultertomente, o texto (aina inédito em portubés o anm

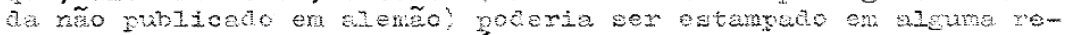

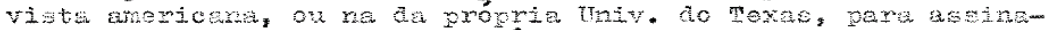

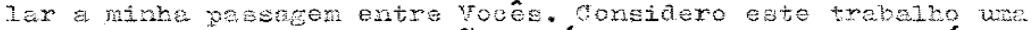

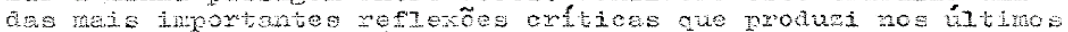

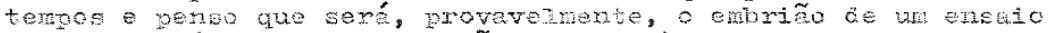

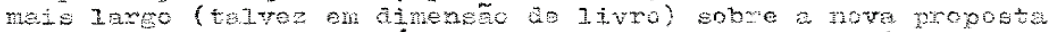

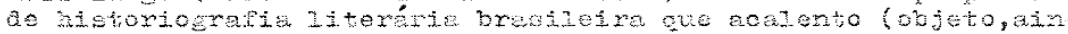
da, do ourso-de ur dejet - gue groforirei en hustin).

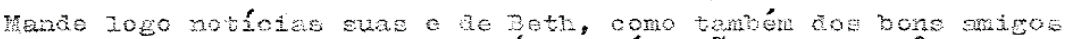

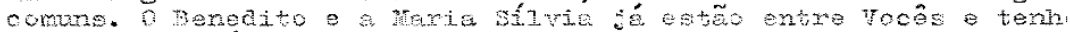

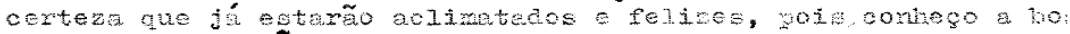

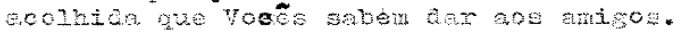

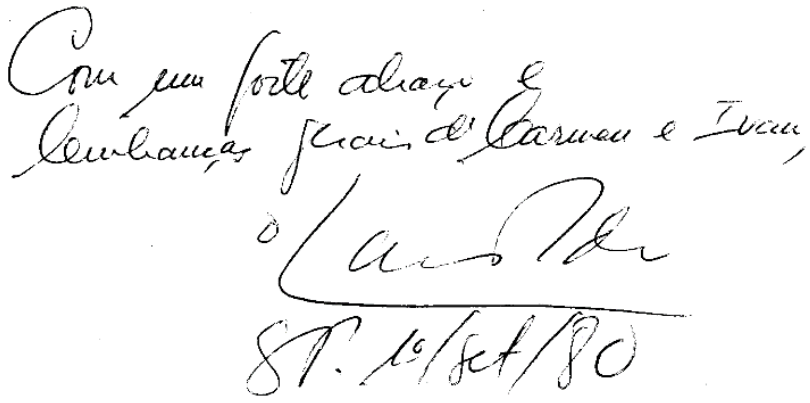

Outro ponto a destacar sobre o vigor da produção haroldiana no período é a conclusão de Galáxias em 1976 e sua publicação em 1984, que, nessa chave, pode ser lido como um marco da pós-utopia (jamais da melancolia) e da magnitude do presente, configurando uma tensão entre utopia e pós-utopia. Os ensaios de Marjorie Perloff (1996; 2012) sobre o poema atestam a força criativa da obra e os diálogos com Pound e Octavio 
Paz que dele podem ser apreendidos em termos de opções formais. Desse modo, a pós-utopia, elaborada pela primeira vez em 1979, não tem nada do ceticismo de um olhar para o presente, de desespero ou desilusão, não é refém da crise, mas responde a ela, criticamente. A apreciação de uma outra via da leitura da tradição e sua mobilização por Haroldo pode fazer avançar um pouco mais a questão. Trata-se da poética sincrônica.

\section{A poética sincrônica e a pós-utopia}

No início dos anos 1960, os poetas concretos tomam contato com os futuristas russos e com os estudos dos formalistas. É de 1961 o adendo ao plano-piloto: "Só há arte revolucionária em forma revolucionária" (Campos, Pignatari e Campos, 2006). Também data do início dos anos 1960 o contato com Roman Jakobson, que publica nesse momento o famoso "Linguística e poética" (1960). ${ }^{19}$ A partir de 1968, depois da visita de Jakobson ao Brasil, as relações entre o poeta da linguística e Haroldo de Campos se aprofundam (Machado, I., 2007). Desse contato, toma corpo um conceito de leitura crítica do passado que será largamente usado pelo poeta. Como se mencionou na seção anterior, na medida em que a reflexão sobre a pós-utopia avança, passa a atender à necessidade de incorporar ao procedimento de leitura fornecido pelo estabelecimento do paideuma como uma concepção de revisão do passado.

Segundo Haroldo de Campos, a poética sincrônica é "uma poética situada, necessariamente engajada no fazer de uma determinada época, e que constitui o seu presente em função de uma escolha ou construção do passado" (Campos, 1997, p. 243, grifo nosso). A conceituação da poética sincrônica é feita em vários momentos da obra haroldiana e um dos primeiros textos a respeito é "Poética sincrônica", publicado no Correio da Manhã, em 19 de fevereiro de 1967,20 em que Haroldo propõe haver modos de criação sincrônica na poesia concreta e em Gregório de Matos, Sousa Caldas, Odorico Mendes, para citar alguns (Campos, 1977b, p. 209) O conceito é fruto de uma "livre aplicação" das ideias de Roman Jakobson (1977b, p. 213) acerca da substituição dos estilos na história literária, relacionando-se também à articulação do passado proposta por

\footnotetext{
${ }^{19}$ O ensaio foi traduzido e publicado em português na obra Linguística e comunicação (Jakobson, 1967).

${ }^{20}$ Utiliza-se aqui a reprodução do texto presente em A arte no horizonte do provável (Campos, 1977b).
} 
Benjamin e que visa à reorganização das reminiscências passadas como "relampejam" (Benjamin, 1996, p. 202).

Marcos Siscar (2014), em um dos mais relevantes artigos sobre pósutopia em Haroldo de Campos publicados desde o ensaio fundador de Italo Moriconi, citado anteriormente, aponta para o fato de que a poética sincrônica, em Haroldo, é instrumental e se afasta "da tentativa de autodefinição indireta" de Octavio Paz (1996a) que, por sua vez, é hermenêutica. Apesar das contribuições feitas por Siscar, neste artigo propõe-se um afastamento de suas considerações, pois é fundamental notar, de outro ponto de vista, que a poética sincrônica é a elaboração da noção, esta sim instrumental, de paideuma. Com ela, não se trata mais de uma "utilidade imediata do passado" (Siscar, 2014, p. 429), no sentido do make it new poundiano, mas de uma reconsideração do valor do passado como potencial meio de construção de um presente possível: não é uma estratégia de leitura, mas uma concepção de leitura. A poética sincrônica é ancorada também no pensamento benjaminiano, autor que chega ao Brasil nesse período, por meio da contribuição dos concretos, entre outros.

Ainda sob essa perspectiva, vale notar que a poética sincrônica não está em Haroldo "ao longo de toda a sua carreira" (Siscar, 2014, p. 427), mas ingressa na reflexão do poeta a partir da segunda metade dos anos 1960, uma década depois do plano-piloto, embora, como já se sublinhou, a preocupação em revisitar criticamente o passado fosse uma das tônicas do concretismo a partir do paideuma. Haroldo publica seu primeiro livro em 1949, e o artigo sobre poética sincrônica em 1967; Jakobson publica o ensaio sobre a função poética em 1960. É, pois, o já poeta amadurecido e revisor de suas próprias concepções que propõe o conceito em um contexto de interdito no país, em que a própria vanguarda será posta em questão por toda uma geração de jovens nos anos 1960 aqui e na Europa, sobretudo na França, quando se chega à compreensão de que era tempo de valorizar o presente para escapar de um futuro opressor, "quimérico" (Paz, 2013). É nesse sentido que tal conceito se aproxima (não como mera reprodução) e dialoga, em termos de alteridade, de outridade, com as reflexões de Paz. E é por isso que Haroldo, no ensaio sobre a pós-utopia, escrito em homenagem aos 70 anos do poeta mexicano, propõe com bastante plausibilidade a aproximação. Some-se a isso o fato de Jakobson ser uma opção teórica comum para ambos os poetas.

Ao inscrever os poetas da tradição em suas obras, Haroldo de Campos caracteriza, simultaneamente, a possibilidade de sua 
sobrevivência e a impossibilidade de sua existência verdadeira a não ser pela recriação, pelo restauro inventivo, pela transcriação que pode ser lida como um certo trabalho de luto. Para aqueles que vêm nisso um poeta "conservador" nos últimos anos, porque se volta mais à leitura da tradição, é bom lembrar que ela já pulsava fortemente em $O$ auto do possesso (1950). Haroldo segue um caminho, "busca-se na busca" como no verso de A máquina do mundo repensada (2000). Lembre-se ainda que não é possível ler nesse poema o poeta das ilusões perdidas. O mesmo Norbert Wiener, criador da cibernética, mencionado logo à primeira linha de "Contexto de uma vanguarda", em Teoria da poesia concreta (Campos, 2006, p. 209), é retomado, 40 anos depois, em A máquina do mundo repensada, ainda que pese a diferença da leitura: desse ponto de vista, talvez não seja um poeta envelhecido e tomado de um pathos apocalíptico que escreve (Siscar, 2014), mas o sincrônico Haroldo que põe, no mesmo poema, do fim da vida, Mallarmé em diálogo com o diabo Maxwell, a partir da cibernética, retomando as leituras dos anos de 1960. A mudança entre 1960 e 2000 não se deve a uma alteração de rota, mas ao aprofundamento de uma perspectiva, como alternativa ao arrefecimento das utopias e à impossibilidade de manutenção da vanguarda, que aliás, como tal, não se poderia manter por longo tempo, pois se trata de uma reação à ordem vigente que guarda seu esgotamento em si mesma.

Em A máquina do mundo repensada, Haroldo de Campos empreende uma aproximação entre poesia e ciência. Da perspectiva do poema e por um desdobramento da leitura, as vanguardas podem ser aproximadas a uma explosão do tipo supernova, pois visam ao arrebatamento do mundo pelo estilhaço da ordem artística (mas não apenas dela) vigente. Alguns elementos da tradição, todavia, resistem.

Assim, se a pós-utopia coloca-se em termos políticos e revela a impossibilidade da vanguarda tal qual se constituiu em meados dos anos de 1950, no entanto, não abandona o engajamento. É preciso notar que a leitura do passado e sua ancoragem no presente são marcas do poeta desde o concretismo e se acentuam com a poética sincrônica de tal modo que se poderia perguntar se não é o estabelecimento desse conceito, tal qual as citações aqui reproduzidas deixam entrever, que garante ao poeta as reflexões sobre a pós-utopia. Não será a poética sincrônica pós-utópica e, ao mesmo tempo, não será ela o que assegura, para Haroldo, a leitura e reinvenção da tradição em termos da pós-utopia? 


\section{História e pós-utopia: constelações e agoridade para concluir}

Retome-se o final do ensaio "Poesia e modernidade: da morte do verso à constelação. O poema pós-utópico":

Tenho dito, em mais de uma oportunidade, que a "poesia concreta" dos anos 50 e 60, [...] ensinou-me a ver o concreto na poesia; a transcender o "ismo" particularizante, para encarar a poesia, transtemporalmente, como um processo global e aberto de concreção sígnica, atualizando de modo sempre diferente nas várias épocas da história literária e nas várias ocasiões materializáveis da linguagem (das linguagens). Safo e Bashô, Dante e Camões, Sá de Miranda e Fernando Pessoa, Hölderlin e Celan, Góngora e Mallarmé são, para mim, nessa acepção fundamental, poetas concretos (Campos, 1997, p. 268-269).

Essa declaração, extraída da página final do ensaio, resume de modo incisivo a postura de Haroldo de Campos em relação à leitura de literatura e à busca da "concreção sígnica" da palavra poética. Não se separa, em Haroldo, a vanguarda da leitura da tradição, embora ambas, ao longo dos anos de sua "atividade poetária", tenham assumido diferentes configurações. Ao contrário do que se poderia pensar sobre esse fragmento - muitas vezes tido como um dos poucos momentos em que o poeta trata, efetivamente, da pós-utopia nesse ensaio -, o que o excerto revela é uma coerência com aquilo que vinha sendo dito no corpo do texto desde o início.

Além disso, é inevitável não chamar a atenção do leitor para outra citação, feita nas primeiras páginas do presente artigo, relativa ao texto de 1960:

Os grandes poetas da língua, na fase áurea do mundo luso, como Sá de Miranda e Camões, não foram porventura homens contemporâneos em seu tempo, vivendo com a informação adequada, importando provençais, italianos e espanhóis, e exportando poesia em língua portuguesa criativa e qualitativamente enquadrada no contexto da época? (Campos, 2006, p. 2011).

Como se vê, há que se repensar o que efetivamente e é nomeado como pós-utopia pela leitura do conjunto da obra do poeta e pode ser produtivo pensá-la em associação a uma utopia pessoal, fáustica, que sempre caminhou ao lado da vanguarda e que ganha espaço, justamente, no contexto pós-utópico (Martha-Toneto, 2012). Fáustica - 
porque Fausto revela o comportamento humano transgressor, não conformista - é uma figura muito cara a Haroldo de Campos.

A vertente fáustica não tem o tom imperativo da vanguarda, mas torna-se pós-utópica, vai além da utopia, porque é um projeto de ação que se opõe à imutabilidade da realidade (Heise, 2001, p. 48,54). Assim é que a razão antropofágica de Haroldo de Campos atua de modo dialético e tensiona a utopia do concretismo, que sempre marcará seu trabalho, mesmo que indiretamente, e a utopia fáustica, que se adensa no contexto pós-utópico. Em 1960, o concretismo estava na efervescência, e Haroldo retoma quase que sem alterações, em 1984, por ocasião da homenagem a Octavio $\mathrm{Paz}$, a menção aos poetas do cânone feitas naquele ensaio. Parece que isso vale, no mínimo, alguma consideração quando se trata simplesmente de afirmar que ele passou a ser, com os anos, pós-utópico, ainda que o poeta possa deixar essa margem para a leitura no próprio ensaio sobre a pós-utopia. Não terá sempre existido uma atmosfera de pós-utopia em seu trabalho, garantida pela sistemática leitura do passado?

Talvez seja generalizador afirmar que o ensaio é: "Conhecido, sobretudo, pelos seus últimos parágrafos - isto é, pela parte que caracteriza o momento pós-vanguardista, praticamente dispensando as demais seções" (Siscar, 2014, p. 427). Do ponto de vista aqui adotado, é arriscado desconsiderar o histórico feito pelo poeta desde o início do ensaio, uma vez que é o "corpo" do texto que permite, como se procurou demonstrar, a avaliação das tensões utópicas na obra e no pensamento haroldianos; tensões entendidas aqui em sentido positivo, problematizadoras da própria noção de pós-utopia. Pontua, ainda, Marcos Siscar:

"Poesia e modernidade" busca preparar o campo para uma operação que é, ao mesmo tempo, explicitamente, uma superação da vanguarda e, implicitamente, o reforço de sua lógica. [...] Já apontei a desproporção que repousa entre o magro final do texto (momento da "constelação" e do poema "pós-utópico") e seu corpo colossal, todo tatuado com as marcas da militância concretista, estrategicamente esculpido para dar à vanguarda o lugar e a função do predecessor do contemporâneo, aquilo que realiza seu próprio fim (Siscar, 2014, p.430-431).

Em sentido distinto, parece plausível defender que não há um reforço da lógica da vanguarda, mas, sim, o reforço de uma atitude utópica que, em Haroldo, existe para além da vanguarda. Se não há 
vanguarda sem utopia, é bastante possível haver utopia sem que haja, necessariamente, vanguarda, basta observar os momentos em que a utopia se fez presente ao longo da história e aqueles em que houve vanguarda. A utopia é maior que a vanguarda. A escolha lexical do excerto acima, muito haroldiana -"magro", "colossal", "tatuado", "militância", "esculpido" - indica uma opção de leitura que imprime o tom de tombeau ao texto de Haroldo distinta desta apresentada aqui. O final do texto (melhor dizer contundente a magro) não necessariamente é desproporcional ao "corpo colossal", até porque, ao longo do ensaio, o movimento é de avaliar a vanguarda, suas possibilidades e sua relação com a crise das ideologias. Para Siscar, "Por essa razão, o ensaio pode ser lido como tributo a um tempo concluído - uma espécie de tombeau das vanguardas" (2014, p. 426). Argumento mais bem explicado no rodapé dessa mesma página:

Considerar o texto de Haroldo como um tombeau (segundo a tradição do poema que faz elogio fúnebre do célebre desaparecido) seria um modo de identificar afinidades entre o trabalho ensaístico e o pathos apocalíptico que a obra do poeta passou a assumir após a publicação de Galáxias (1984), sobretudo, em seus últimos livros (Siscar, 2014, p. 426).

Da perspectiva que se adota neste artigo, parece tratar-se mais de um tombeau construído por algumas leituras do ensaio de Haroldo que de um tombeau construído por Haroldo; um leitor atento do poema A máquina do mundo repensada (2000) verá ali que o que se afirma não é um pathos apocalíptico, mas ao enfrentar o momento do límen do milênio e sua situação apocalíptica, a poesia surge como alternativa a isso, porque se situa em seu presente e, a partir dele e da revisão crítica do passado, enuncia. Propositalmente marcado de preciosismo e pomposidade, como apontou criticamente Paulo Franchetti (2000), o poema encena, justamente pelo tom, uma determinada linguagem; performatiza o fim, o nexo, para impulsionar a leitura ao início. Talvez seja apressado considerar também apocalípticos os trabalhos voltados para as traduções de textos bíblicos - se vieram à luz apenas postumamente, a pesquisa junto ao acervo do poeta mostra que essa preocupação já lhe era fundamental muito tempo antes. ${ }^{21}$

${ }^{21}$ Ver, no acervo, por exemplo, as anotações feitas na primeira edição de "A formação da literatura brasileira", de Antonio Candido. 
Tampouco parecem disfóricos livros como a Educação dos cinco sentidos, sobre o qual David Jackson aponta a possibilidade de um "Bildungspoesie de Haroldo" que é "também a história de uma viagem pessoal, nessa esfera mágica de comunicação e relacionamento por meio do poético [...]. Haroldo encontra tudo aberto a duplas e múltiplas leituras. Pinta, esculpe, ri. Pula como o tigre na volátil primavera de sua invenção" (Jackson, 2013, p.10-12). E se é possível ler em entremilênios, livro póstumo, de 2009, a passagem do tempo, natural a um poeta como Haroldo, não se pode deixar de ler ali também um alerta vigoroso do poeta citadino em "são paulo", para quem "a musa não medusa". ${ }^{22}$ Observa-se nesses textos a passagem do tempo, a obra (sempre) em construção, de um poeta maduro, mas carregada do vigor da leitura da tradição.

Pode ser precipitado chamar de apocalíptica uma obra que rendeu a publicação de dois dos mais relevantes ensaios do poeta marcados de uma reflexão vigorosa e ativa e, por que não dizer, de uma conclamação à crítica: Da razão antropofágica: diálogo e diferença na cultura brasileira, de 1981, já mencionado; e o polêmico O sequestro do barroco na formação da literatura brasileira (1989); além de poemas como Galáxias e A máquina do mundo repensada. Aliás, a obra que mais ilumina e favorece a compreensão da dupla utopia em Haroldo é A máquina do mundo repensada. Esse poemalivro, composto de decassílabos em terza rima, não significa uma desistência da inventividade ou dos ideais do primeiro Haroldo, pelo contrário, reafirma uma dicção constante em sua trajetória barrococoncretista e a (trans)ilumina, pois esta obra é um holofote dirigido a todo um passado literário, histórico e pessoal do poeta.

No poema há um aspecto crucial para delimitar melhor a utopia fáustica de Haroldo, que é a tentativa de reconstrução de uma história literária, da qual ele, enquanto poeta, é fruto e, ao mesmo tempo, fundador, não só porque cria seus precursores, mas porque funda uma concepção de poesia a partir de reconstrução seletiva do cânone e das mais distintas formas de saber que habitam seus (inter)textos. Quando escolhe a matéria de seu canto, Haroldo não busca outra coisa senão o "grito que um galo antes", mas este canto volta-se sobre si mesmo, é um "ur-canto": um canto primeiro e um ruído de fundo, simultaneamente,

${ }^{22}$ Ao contrário de algumas leituras de entremilênios, penso haver ali não apenas disforia e passagem do tempo, mas ainda a pressa e o vigor da utopia, como nos poemas mencionados anteriormente. 
a ecoar as várias vozes da tradição, deixando sobressair, entretanto, a sua voz, singular e única, autoral, que vem à tona, como ele mesmo diz a propósito da tradução, pela "vivisseção implacável" no corpo dos textos lidos por ele (Campos, 2005b), resultado do que se poderia chamar um pacto "mefistofélico" de leitura.

Quando Haroldo recupera um texto de 1960 em 1984 para tratar dos poetas do cânone e de sua importância, conforme ressaltado há pouco, mostra que, dialeticamente, essa relação com o cânone foi se articulando em seu projeto. E isso só aconteceu porque ela sempre, de algum modo, fez parte dele, não como vanguarda concretista, mas como um desejo íntimo, um sentimento de "instinto de nacionalidade" que integra a literatura brasileira e a universal, em trilha sutilmente apontada por Machado de Assis e recuperada pelo poeta no ensaio "The ex-centric's viewpoint: tradition, transcreation, transculturation" (Campos, 2005b).

Ao se assumir que a leitura da tradição, colocada aqui ao lado da pós-utopia, é, para Haroldo, tão utópica quanto o concretismo, assume-se também uma perspectiva que desafia aspectos do que diz o poeta em seu ensaio, no sentido de que se empreende a leitura deste colocando a obra em perspectiva. Esse é um caminho interessante para entender as propostas da agoridade. Haroldo jamais deixou de ser de vanguarda; sempre assumiu a dimensão crítica da utopia como algo crucial ao seu trabalho desde os primeiros livros até o último. De um lado, a grande revolução no sentido de ruptura; de outro, a revolução no sentido de volta, como a revolução solar; de um lado o futuro, pois quem escreve tem duas batalhas, a luta contra a morte, pensada aqui em termos simbólicos, evidentemente, e o desejo de permanência, portanto, futuro.

É preciso considerar a heresia, em sentido adorniano (Adorno, 2003), do ensaio de Haroldo de Campos sobre o poema pós-utópico, seu gesto mefistofélico, a tensão dialética a partir da qual a solução não é a pós-utopia, mas a integração desta a uma utopia fáustica, que se mantém até os últimos projetos e se amalgama à utopia de vanguarda arrefecida. Não há como separar, na obra haroldiana, esse dois lados, porque a poesia, em Haroldo, é sempre forma de resistência da palavra e da humanidade ao agreste da existência sustentada por galáxias e constelações utópicas. 


\section{Referências}

ADORNO, Theodor (2003). O ensaio como forma. In: ADORNO, Theodor. Notas de Literatura I. São Paulo: Editora 34, p. 45-60.

AGUILAR, Gonzalo (2005). Poesia concreta brasileira: as vanguardas na encruzilhada modernista. São Paulo: Edusp.

BARBOSA, Jorge Luiz (2003). A cidade do devir na utopia de Thomas Morus. GEOgraphia, Rio de Janeiro, ano V, n. 10, p. 25-45.

BENJAMIN, Walter (1996). Sobre o conceito da história. In: BENJAMIN, Walter. Obras escolhidas: magia e técnica, arte e política. São Paulo: Brasiliense, v. 1.

BLOCH, Ernest (1980). El principio esperanza. Tradução de Felipe González Vicen. Buenos Aires: Aguilar. 3 v. (Biblioteca de Iniciación Filosófica).

BLOCH, Ernest (2005). O princípio esperança. Tradução de Nélio Schneider; Werner Fucks. Rio de Janeiro: Contraponto.

BÜRGER, Peter (2008). Teoria da vanguarda. Tradução de José Pedro Antunes. São Paulo: Cosac \& Naify.

CAMPOS, Augusto; PIGNATARI, Décio; CAMPOS, Haroldo de (2006). Teoria da poesia concreta: textos críticos e manifestos (1950-196). São Paulo: Ateliê.

CAMPOS, Haroldo de (1950). O auto do possesso. Clube de Poesia.

CAMPOS, Haroldo de (1977a). Comunicação na poesia de vanguarda. In: CAMPOS, Haroldo de. A arte no horizonte do provável. São Paulo: Perspectiva, p. 131-154.

CAMPOS, Haroldo de (1977b). Por uma poética sincrônica. In: CAMPOS, Haroldo de. A arte no horizonte do provável. São Paulo: Perspectiva, p. 205-231.

CAMPOS, Haroldo de (1980). Carta a David Jackson. São Paulo, $1^{\circ}$ set.

CAMPOS, Haroldo de (1992a). Da razão antropofágica: diálogo e diferença na literatura brasileira. In: CAMPOS, Haroldo de. Metalinguagem e outras metas. São Paulo: Perspectiva, p. 231-257.

CAMPOS, Haroldo de (1992b). Minha relação com a tradição é musical. In: CAMPOS, Haroldo de. Metalinguagem e outras metas. São Paulo: Perspectiva, p. 257-269.

CAMPOS, Haroldo de (1994). Um olhar sobre a América hispânica. Entrevista com o crítico e poeta Haroldo de Campos. (Entrevista a Rodolfo Mata). Jornal de Poesia, Fortaleza. On-line. Disponível em: https://goo.gl/DBb9EQ Acesso em: 20 jun. 2016. 
CAMPOS, Haroldo de (1997). Poesia e modernidade: da morte do verso à constelação. O poema pós-utópico. In: CAMPOS, Haroldo de. O arco-íris branco. São Paulo: Imago, p. 243-270.

CAMPOS, Haroldo de (2000). A máquina do mundo repensada. São Paulo: Ateliê, 2000.

CAMPOS, Haroldo de (2004). Galáxias. 2. ed. São Paulo: 34.

CAMPOS, Haroldo de (2005a). Bufoneria transcendental: o riso das esferas. In: CAMPOS, Haroldo de. Deus e o diabo no Fausto de Goethe. São Paulo: Perspectiva.

CAMPOS, Haroldo de (2005b). The ex-centric's viewpoint: tradition, transcreation, transculturation. In: JACKSON, Keneth David. Haroldo de Campos: a dialogue with the Brazilian concrete poet. Edited by David Jackson. Oxford: Centre for Brazilian Studies, p.17-27

CAMPOS, Haroldo de (2006). Contexto de uma vanguarda. CAMPOS, Augusto; PIGNATARI, Décio; CAMPOS, Haroldo de (2006). Teoria da poesia concreta: textos críticos e manifestos (1950-196). São Paulo: Ateliê.

CANDIDO, Antonio (1959). A formação da literatura brasileira. Rio de Janeiro: Martins.

FRANCHETTI, Paulo (2000). Funções e disfunções da máquina do mundo. O poeta Haroldo de Campos retoma assunto tratado por Camões e Drummond. Resenha de A máquina do mundo repensada. O Estado de S. Paulo, Caderno 2, p. 210, 24 set.

FRANCHETTI, Paulo (2012). Alguns aspectos da teoria da poesia concreta. 4. Ed. rev. ampl. Campinas: Editora da Unicamp.

FREUD, Sigmund (2010). Além do princípio do prazer e outros textos (19171920). Obras completas. São Paulo: Companhia das Letras, v. 14.

GAGNEBIN, Jeanne-Marie (2014). Limiar, aura e rememoração: ensaios sobre Walter Benjamin. São Paulo: 34.

HEISE, Eloáo (2001). A lenda do doutor Fausto em relação dialética com a utopia. In: IZARRA, L. Z. (Org.). A literatura da virada do século: fim das utopias? São Paulo: Humanitas; Fapesp, p. 47-56.

JACKSON, Kenetth David (2005). Haroldo de Campos and the poetics of invention In: JACKSON, Kenetth David. Haroldo de Campos: a dialogue with the Brazilian concrete poet. Edited by David Jackson. Oxford: Centre for Brazilian Studies, p. 17-27.

JACKSON, Kenetth David (2013). A educação do sexto sentido: poesia e filosofia em Haroldo de Campos. Prefácio. In: CAMPOS, Haroldo de. Educação dos cinco sentidos. São Paulo: Iluminuras, p. 9-13. 
JAKOBSON, Roman (1960). Linguistics and poetics. In: SEBEOK, Theodor A. Style in language. Cambridge: MIT.

JAKOBSON, Roman (2015). Linguística e comunicação. São Paulo: Cultrix.

LIMA, Luís Costa (2005). Haroldo, o multiplicador. In: MOTTA, Leda Tenório da. Céu acima: um tombeau para Haroldo de Campos. São Paulo: Perspectiva.

LIMA, Luís Costa (2009). O controle do imaginário $\mathcal{E}$ a afirmação do romance. São Paulo: Companhia das Letras.

MACHADO, Carlos Eduardo Jordão (2008). Sonhos diurnos e geografia: sobre o princípio esperança de Ernest Bloch. Resenha. Trans/Form/Ação, Marília, v. 31, n. 1, p. 205-213. Disponível em: https://goo.gl/jzH4gS. Acesso em: 12 nov. 2015.

MACHADO, Irene (2007). O filme que Saussure não viu: o pensamento semiótico de Roman Jakobson. Vinhedo: Horizonte.

MARTHA-TONETO, Diana Junkes (2012). Haroldo de Campos e a utopia da escritura original. FronteiraZ, São Paulo, n. 9, p. 175-187.

MARTHA-TONETO, Diana Junkes (2014). As razões da máquina antropofágica: poesia e sincronia em Haroldo de Campos. São Paulo: Editora da Unesp.

MORICONI, Italo (1986). O pós-utópico: crítica do futuro e da razão imanente. Revista Tempo Brasileiro, Rio de Janeiro, v. 84, jan./mar., p. 69-85

PAZ, Octavio (1996a). Literatura de fundação. In: PAZ, Octavio. Signos em rotação. São Paulo: Perspectiva, p. 125-132.

PAZ, Octavio (1996b). Invenção, desenvolvimento, modernidade. In: PAZ, Octavio. Signos em rotação. São Paulo: Perspectiva, p.133-139.

PAZ, Octavio (2013). Os filhos do barro. São Paulo: Cosac \& Naify.

PÉCORA, Alcir (2005). Big Bang, sublime e ruína. In: MOTTA, Leda Tenório da. Céu acima: um tombeau para Haroldo de Campos. São Paulo: Perspectiva.

PERLOFF, Marjorie (1996). Concrete prose: Haroldo de Campos Galáxias and after. Disponível em: https://goo.gl/hnaNC4 Acesso em: 20 jul. 2016.

PERLOFF, Marjorie (2012). Refiguring the Poundian ideogram: from Octavio Paz's Blanco/Branco to Haroldo de Campos's Galáxias. Modernist Cultures, v. 7, n. 1, p. 40-55. DOI: http://dx.doi.org/10.3366/mod.2012.0027

PERRONE, Charles (1996). Seven faces: Brazilian poetry since modernism. London: Duke University Press.

PERRONE-MOISÉS, Leyla (2003). Altas literaturas. São Paulo: Companhia das Letras. 
POGGIOLI, Renato (2011). Teoría del arte de vanguardia. Tradução: Rodolfo Mata.Cidade do México: Universidade Autônoma do México.

POUND, Ezra (1970). ABC da literatura. São Paulo: Cultrix.

SCHWARTZ, Jorge (2008). Vanguardas Latino-americanas. São Paulo: Edusp.

SIMON, Iumna; DANTAS, Vinicius (1985). Poesia ruim; sociedade pior. Novos Estudos Cebrap, São Paulo, n. 12, jun./dez.

SISCAR, Marcos (2014) O tombeau das vanguardas: a "pluralização das poéticas possíveis" como paradigma crítico contemporâneo. Alea, Rio de Janeiro, v. 16, n. 2, p. 421-447, jul./dez.

SISCAR, Marcos (2016). Ciranda da poesia: Haroldo de Campos por Marcos Siscar. Rio de Janeiro: Eduerj.

TELES, Gilberto Mendonça (2012). Vanguarda europeia e modernismo brasileiro. Rio de Janeiro: José Olympio.

VIEIRA, Antonio Rufino (2007). Princípio esperança e a herança intacta do marxismo em Ernest Bloch. In: COLÓQUIO INTERNACIONAL MARX ENGELS, 5., Unicamp, 6 a 9 nov. On-line. Campinas: Cemarx. Disponível em: http://www.unicamp.br/cemarx/anais_v_coloquio_arquivos/arquivos/comu nicacoes/gt1/sessao6/Antonio_Rufino.pdf. Acesso em: 10 nov. 2015.

WEINTRAUB, Fabio (2013). O tiro, o freio, o mendigo e o outdoor: representações do espaço urbano na poesia brasileira pós-90. Tese (Doutorado em Letras) Universidade de São Paulo, São Paulo.

Recebido em 11 de agosto de 2016.

Aprovado em 31 de outubro de 2016.

\section{resumo/abstract/resumen}

\section{Constelações pós-utópicas: sobre a poesia de Haroldo de Campos}

Diana Junkes Bueno Martha

Se observado a partir da relação com o cânone, o trabalho criativo de Haroldo de Campos vai além do concretismo, sugerindo a existência de uma articulação entre a utopia de vanguarda e outra, mais amplamente voltada para o diálogo e reinvenção da tradição, a que se pode chamar utopia fáustica e que pode ser associada à pósutopia, apresentada pelo poeta em Poesia e modernidade, da morte do verso à constelação, 
o poema pós-utópico. A partir de um movimento de revisão do princípio-esperança da vanguarda, das leituras que realiza da obra de Walter Benjamin, estimulado, ainda, pela leitura de Os filhos do barro de Octavio Paz, Haroldo de Campos defende nesse ensaio, como já fizera em ensaios anteriores, a necessidade de uma poesia da agoridade que atenda a um contexto pós-utópico. Assumindo posição distinta daquela proposta por parcela da fortuna crítica dedicada ao estudo da pós-utopia na obra haroldiana, que nota tom funesto em seus últimos poemas, em virtude do arrefecimento utópico, este artigo pretende levantar a hipótese de que talvez seja mais interessante tomar as relações entre utopia e pós-utopia em sua obra, dialeticamente, defendendo que ambas integram-se mutuamente e têm, na mobilização do passado, em sentido benjaminiano, uma chave interessante de leitura. Propõe-se, ainda, que a pós-utopia não seja abordada do ponto de vista da crise da poesia, mas, antes, como resposta e posicionamento do poeta em relação à crise, por isso marcadamente crítica e inventiva.

Palavras-chave: pós-utopia, tradição, vanguarda, poesia contemporânea, Haroldo de Campos.

\section{Post-utopian constelations: about Haroldo de Campos' poetry}

\section{Diana Junkes Bueno Martha}

The creative work of Haroldo de Campos goes beyond concretism, if it is considered from the relationship with the canon, suggesting the existence of a link between avant-garde utopia and a more broad one, focused on the dialogue and reinvention of tradition, which we can call a Faustian utopia; and which can be associated to the post-utopia, presented by the poet in the essay "Poesia e modernidade, da morte do verso à constelação $\mathrm{O}$ poema pós-utópico." Motivated by a desire to review the vanguard's hope-principle, Walter Benjamin's readings and also inspired by Octavio Paz's "Children of the mire," Haroldo de Campos argues, as he had in previous texts, that in a post-utopian context it is crucial that poetry contemplate the present time, criticizing the mere idea of the future. In this article, we assume a position contrary to that of critics that have focalized Campos' utopia. Instead we put forth the hypothesis that it may be more productive to explain the utopia and post-utopia in his work in dialectical terms, which integrate both principles. According to this perspective, the past may be considered in a Benjaminian sense, as an interesting mode of interpretation. It also proposes that post-utopia is not addressed from the point of view of a poetry of crisis, but rather as a response and an articulation of the poet's position regarding crisis, and is, as such, markedly critical and inventive.

Keywords: post-utopia, tradition, vanguard, contemporary poetry, Haroldo de Campos. 


\section{Constelaciones post-utópica: acerca de la poesía de Haroldo de Campos}

Diana Bueno Junkes Martha

Si se ve desde la relación con el canon, el trabajo creativo de Haroldo de Campos va más allá de lo concreto, lo que sugiere la existencia de un vínculo entre la utopía vanguardista y un sentido más amplio centrado en el diálogo y la reinvención de la tradición, a lo que se le puede llamar la utopía fáustica y que pueden estar asociado con la post-utopía, presentada por el poeta en Poesia $e$ modernidade, da morte do verso à constelação, o poema pós-utópico. A partir de un movimiento de revisión del principio-esperanza de la vanguardia, de las lecturas que realiza de la obra de Walter Benjamin, estimulado también por la lectura de Los hijos del limo de Octavio Paz, Haroldo de Campos sostiene en este ensayo, como lo había ya hecho en ensayos anteriores, la necesidad de una poesía de la agoridad que corresponda a un contexto post-utópico. Asumiendo una posición diferente de la propuesta por parte de la fortuna crítica dedicada al estudio de la post-utopía en el trabajo haroldiano que encuentra un tono siniestro en sus últimos poemas, debido a un enfriamiento utópico, este artículo tiene como objetivo proponer la hipótesis de que podría ser más interesante tomar dialécticamente las relaciones entre la utopía y la post-utopía en su obra, argumentando que ambas se integran mutuamente y tienen, en la movilización del pasado, en el sentido benjaminiano, una clave de lectura interesante. Se propone, aún, que la post-utopía no sea abordada desde el punto de vista de la crisis de la poesía, sino más bien como una respuesta y como un posicionamiento del poeta respecto a la crisis, y por eso marcadamente crítica e inventiva.

Palabras clave: post-utopía, tradición, vanguardia, poesía contemporánea, Haroldo de Campos. 